\title{
Chinese translations on bmj.com
}

\author{
Readers will begin to see some articles translated into Mandarin
}

\section{Juliet Dobson digital content editor, Daoxin Yin China editor, Kamran Abbasi executive editor}

The BMJ, London, UK

The BMJ's readership in China is growing. Around 30000 people from China now visit bmj.com each month. While this is a small proportion of China's total population of almost 1.4 billion, a drop in the ocean will one day grow into a sea. Although we may no longer be divided by geography or the internet, we remain divided by language. We want to move a step closer to our Chinese readers with a new initiative to publish selected pdfs in Mandarin on bmj.com.

The BMJ's engagement with China goes back many years. In 1998, we began a monthly Mandarin print edition in partnership with the Chinese Medical Association. This monthly digest features a selection of articles from The BMJ and other journals published by BMJ company. The articles are chosen for local relevance under the direction of the editor of The BMJ's Chinese edition, translated into Mandarin, and sent each month to clinicians in China. It is these translations that we are now beginning to make available on bmj.com.

We will upload translated articles prospectively, although a six month time lag currently exists between an article appearing on bmj.com and it being published in Mandarin in our Chinese print edition. We will also add articles retrospectively so that ultimately all articles published since 1998 in our Chinese print edition will also be available on bmj.com. Articles on bmj.com that are translated carry a prominent banner to direct readers to the Mandarin version. ${ }^{1}$
Aside from these translated articles we now publish more articles by Chinese authors, covering the full range of The BMJ's content, from opinion pieces, ${ }^{2}$ through editorials, ${ }^{3}$ to original research, ${ }^{4}$ and including a new collection of articles discussing medical research in China. ${ }^{5}$ We hope and intend that our China coverage is of interest to readers all over the world. Our new initiative to publish Mandarin translations on bmj.com, however, is a specific attempt to be more welcoming and useful to readers whose first language is Mandarin.

Competing interests: We have read and understood BMJ policy on declaration of interests and have no relevant interests to declare.

Provenance and peer review: Commissioned; not externally peer reviewed.

Prigerson HG, Vaughan SC, Lichtenthal WG. The hidden dangers of a cancer diagnosis. BMJ 2016;354:i4446. doi:10.1136/bmj.i444627581497

2 Ji J. Encouraging patient centred care in China. BMJ Opinion 23 Nov 2017 http://blogs. bmj.com/bmi/2017/11/23/jiafu-ji-encouraging-patient-centred-care-in-china/.

Chen N, Zhang C, Hu S. Strengthening trauma care in China. BMJ 2017;359:55545. doi:10.1136/bmj.j554529259005

4 Weng J, Zhou Z, Guo LT1D China Study Group. Incidence of type 1 diabetes in China, 2010-13: population based study. BMJ 2018;360:;5295. doi:10.1136/bmj.j529529298776 5 Wu Y, Yin D, Abbasi K. China's medical research revolution. BMJ 2017;360:k547.

Published by the BMJ Publishing Group Limited. For permission to use (where not already granted under a licence) please go to http://group.bmj.com/group/rights-licensing/ permissions 